\title{
A NEW FROG FROM THE VIRGIN ISLANDS,
}

\author{
Chapman Grant, Major, U. S. Army.
}

A recent ten-day collecting trip to St. Thomas, St. John, St. James and adjacent keys developed several new locality records and one new frog which may be called:

\section{Fleutherodactylus cochranae sp. nov.}

Type No. 5659. Chapman Grant Collection, 14 April, 1932, St. John Island, V. I.; collector, Chapman Grant.

Diagnosis: Distinguished from the other West Indian Eleutherodactylus by practical absence of vomerine teeth; short obtuse snout; small size of ear and its nearness to eye.

Habitat: St. John and Hassel Island, St. Thomas. Found in the axils of Bromeliads.

Proportions: Slender, medium size, $20 \mathrm{~mm}$.

Description of Co-types: Habitus average, head slightly wider than body, eyes medium; limbs medium, relatively short, heels overlapping when legs are placed at right angles to the body; length vent to heel equal to about vent to posterior part of eyes. Vomerine teeth almost wanting. Tongue large, oval, not notched behind, free about half its length. Nostrils prominent, much closer to tip of snout than to eye; eanthus rostralis not distinct, loreal area sloping, longitudinally concave, indistinct because of warty skin in this area; snout short and obtuse; distance between orbits about $3 / 4$ width 0 ? eye and about equal to eye to half way between nostril and snout; eye medium but equal to distance eye to snout; tympanum small, not distinct above, about $1 / 3$ diameter of eye and nearly adjoins the orbit; fingers free with medium dises graduated, smallest on first finger; area of dise on fourth finger twice that of first; toes with medium dises, fourth and fifth decidedly larger than other three; no webs; tubercles small. Skin coarsely granular on belly which bears a disc, and on lower aspect of thighs; raised line from snout to vent, large warts on head and eyelids symmetrically placed and about five rows warts along dorsum; largest toe disc almost equal to tympanum in area and slightly larger than largest finger disc.

Color and markings: Above generally grayish brown with a cornplicated dark brown pattern, resembling the outstretehed skin of a 
wolf; usually a dark stripe from eye, over tympanum and front leg; rear aspect of thigh and lower surface of tibio-tarsal joint elear seal brown. Below light with fine brown specks on throat and thighs, belly nearly clear.

Measurements of type, which is an average adult: snout to vent 21 $\mathrm{mm}$.; width of head $8 \mathrm{~mm}$.; snout to posterior edge of tympanum $8 \mathrm{~mm}$; leg from vent $26 \mathrm{~mm}$; foreleg from axilla $12 \mathrm{~mm}$; hind foot $10.5 \mathrm{~mm}$.

This species is found in the axils of tree-inhabiting Bromeliads. Thirty or more individuals sometimes being found in one plant. A very few $E$. antillensis were found with these on St. John but none on Hassel Island. This species has certain resemblances to $E$, antillensis, but many $E$. antillensis smaller than many of the present species had their own characteristies well marked. There seem to be many constant differences but the granulation of the lower side is similar.

I submitted this question to Miss Cochran who writes under date of July 12, 1932," "-...-.- is certainly not the young of antillensis. It has no well marked canthus rostralis, its snout is shorter, its ear is considerably nearer to the eye, it has practically no vomerine teeth. and it has no well-marked black reticulations behind the femur-in all of which characters it is decidedly different from Antillensis".

The voice of this species was not heard.

Remarks: Specimens taken, St. John, 210; Hassel Island, 45.

Named in honor of Doris M. Cochran.

This frog bears a stiperficial resemblance to E. gryllus of Puerto Rico in color and markings, but the head is wider in proportion. 